Article

\title{
Quantitative and Qualitative Analysis of Hydrogen Accumulation in Hydrogen-Storage Materials Using Hydrogen Extraction in an Inert Atmosphere
}

\author{
Maria N. Babikhina ${ }^{1, *}$, Viktor N. Kudiiarov ${ }^{1}$ (D), Andrei V. Mostovshchikov ${ }^{2}$ (i) and \\ Andrey M. Lider ${ }^{1}$ \\ 1 Division for Experimental Physics, School of Nuclear Science and Engineering, National Research Tomsk \\ Polytechnic University, Tomsk 634050, Russia; viktor.kudiiarov@gmail.com (V.N.K.); lider@tpu.ru (A.M.L.) \\ 2 Research Laboratory for Super High Frequency Technology, School of Nuclear Science and Engineering, \\ National Research Tomsk Polytechnic University, Tomsk 634050, Russia; pasembellum@mail.ru \\ * Correspondence: m.babihina@mail.ru; Tel.: +7-953-927-3071
}

Received: 10 July 2018; Accepted: 21 August 2018; Published: 28 August 2018

\begin{abstract}
Currently, standard samples with high hydrogen concentrations that meet the requirements of hydrogen extraction in an inert atmosphere are not currently available on the market. This article describes the preparation of Ti-H standard samples and the calibration of RHEN602, a hydrogen analyzer, using LECO (LECO, Saint Joseph, MI, USA). Samples of technically pure titanium alloy were chosen as the material for sample production. The creation procedure includes five main steps: sample preparation (polishing to an average roughness of $0.04 \mu \mathrm{m}$ using sandpaper), annealing, hydrogenation, maintenance in an inert gas atmosphere, and characterization of the samples. The absolute hydrogen concentration in the samples was determined by two methods: volumetric and mass change after the introduction of hydrogen. Furthermore, in-situ X-ray diffraction, temperature programmed desorption (TPD) analysis, and thermogravimetric analysis were used during measurements to investigate the phase transitions in the samples. As a result of this work, a series of calibration samples were prepared in a concentration range up to $4 \mathrm{wt} \%$ hydrogen, optimal parameters for measuring high concentrations of hydrogen. The calibration line was obtained and the calibration error was $10 \%$.
\end{abstract}

Keywords: RHEN602 by LECO; hydrogen; standard samples; titanium alloy

\section{Introduction}

An important task for the extension of the hydrogen economy is the development of promising hydrogen storage materials [1-6]. In order to possess high rates of hydrogen sorption and desorption, advanced hydrogen storage materials should have optimal elemental and phase composition. Additionally, they should accumulate a large amount of hydrogen and be cyclically stable [7-11]. In the matrix, metal hydrides have a high bulk density of hydrogen atoms, a wide range of operating pressures and temperatures, catalytic activity, and are the most used materials for hydrogen storage [12-20]. Intermetallic compounds based on hydride-forming metals—such as $\mathrm{Zr}, \mathrm{Ti}, \mathrm{Pd}$, and $\mathrm{V}$-can accumulate up to four mass \% of hydrogen [21-30] and are widely used for hydrogen storage. Measurement of the hydrogen concentration in hydrogen storage materials is an important stage in the development and testing of materials.

At present, the following methods are used to measure hydrogen concentration in metals: emission spectroscopy, spectrometry with inductively coupled plasma, charged particle activation analysis, mass spectral analysis, high-temperature vacuum annealing with mass spectrometric 
recording of hydrogen, and extraction in an inert gas medium with determination of hydrogen content by means of a thermocondimetric cell along the calibration line [31,32]. The last method has been the most widely used in both scientific laboratories and industries.

The application of the hydrogen extraction method in an inert gas environment makes it possible to determine hydrogen concentration with high accuracy (quantitative analysis) by means of a calibration line, as well as by analyzing the shape of the extraction curve (the number of maxima on the curve, and the width and height of the maximum). The state of hydrogen in the material (qualitative analysis) can be evaluated analogously to the method used for thermally stimulated desorption [33-37]. However, when quantitatively and qualitatively analyzing hydrogen accumulation in storage materials with high hydrogen concentration, two difficulties can arise: incorrect results or unobtainable analysis results.

The first difficulty, regarding incorrect results, is that hydrogen analyzers, whose operation principle is based on the method of extraction in an inert gas medium, are calibrated for reference samples at low concentration. Thus, the hydrogen analyzers of the RHEN series using LECO (LECO, Saint Joseph, MI, USA) [38] are calibrated as reference samples with hydrogen concentrations from 6 to $60 \mathrm{ppm}$, and have a sensitivity of $0.02 \mathrm{ppm}$, with an error in determining small (up to $100 \mathrm{ppm}$ ) hydrogen concentrations not exceeding $10 \%$. When measuring high hydrogen concentrations, however, the measurement error can be significantly greater, since reference samples with low concentrations are used for calibration. To solve this problem, it is necessary to calibrate the analyzer using reference samples with high concentrations. However, such samples are not sold by analyzer manufacturers. As such, it is necessary to prepare samples with known high hydrogen concentrations.

The second difficulty, regarding unobtainable analysis results, occurs when the upper threshold sensitivity of the thermocondimetric cell exceeds its limits. This happens when a sample with high hydrogen content melts very rapidly and a large amount of hydrogen enters the cell in a short period of time. Rapid melting of the analyzed sample occurs during the standardized analysis, as the current passing through the sample immediately provides the maximum value. An increase in the gradual stepwise of amperage in an initial value to its maximum will result in a more gradual extraction of hydrogen, without exceeding the upper threshold of sensitivity for the thermocondimetric cell. This will allow for an analysis of samples with high hydrogen contents, including the analysis of the extraction curve shape and form.

Thus, the samples with known high hydrogen concentrations were prepared in this study. The optimal parameters for analyzing the samples with high hydrogen concentration were selected so that the upper threshold of sensitivity for the thermal conductivity cell would not be exceeded. Using LECO, the hydrogen analyzer RHEN602 was calibrated according to the prepared samples and the selected optimal parameters. The efficiency of the developed technique was tested on various samples of hydrogen storage materials.

\section{Materials and Methods}

The material used for the preparation of samples with known high hydrogen content and tested with the hydrogen analyzer calibration must have a number of properties: High sorption rates under hydrogenation conditions; a stable state of hydrogen without the possibility of desorption under standard temperature and pressure; cost-effectiveness; accessibility; and safety when handling. In this paper, technically pure titanium alloy was chosen as the material that satisfies the above conditions; it has also been thoroughly studied [39-47]. The samples for hydrogenation were made of $3 \mathrm{~mm}$ long wire that was $2.5 \mathrm{~mm}$ in diameter. To produce the calibration samples with high concentration $(4 \mathrm{wt} \%)$, commercially pure titanium powder was used. The introduction of hydrogen was carried out by gas-phase hydrogenation at $600^{\circ} \mathrm{C}$ and under a pressure of $2 \mathrm{~atm}$. To achieve various concentrations of hydrogen with the Gas Reaction Controller, an LPB automated complex was used (Advanced Materials Corporation, Pittsburgh, PA, USA). Different concentrations of hydrogen were achieved by varying the hydrogenation time. Six series of samples were obtained. Each series contained 10 samples with 
the same concentration. It should be noted that as the concentration increased, the saturation time increased linearly (Table 1).

Table 1. The calibration samples series.

\begin{tabular}{cccccc}
\hline Series & $\begin{array}{c}\text { Hydrogenation } \\
\text { Time (min) }\end{array}$ & Concentration (wt \%) & Series & $\begin{array}{c}\text { Hydrogenation } \\
\text { Time (min) }\end{array}$ & Concentration (wt \%) \\
\hline 1 & 55 & $0.643 \pm 0.032$ & 4 & 140 & $1.559 \pm 0.078$ \\
2 & 70 & $1.068 \pm 0.053$ & 5 & 160 & $1.860 \pm 0.093$ \\
3 & 120 & $1.125 \pm 0.056$ & 6 & 210 & $4.0 \pm 0.1$ \\
\hline
\end{tabular}

The concentration was determined by two methods: volumetric and mass change after the introduction of hydrogen [48-52]. The concentration of the resulting series of the calibration samples are shown in Table 1.

Temperature programmed desorption analysis was carried out with Stanford Research Systems' quadrupole mass spectrometer RGA100, which is part of the equipment used in the advanced Gas Reaction Controller LPB complex (Advanced Materials Corporation, Pittsburgh, PA, USA). During gas phase hydrogenation, phase transitions in the material were studied in situ at Precision Diffractometry II, located at the Boreskov Institute of Catalysis in the Siberian Brach of the Russian Academy of Sciences (SB RAS), on the 6th channel of synchrotron radiation of the VEPP-3 electron storage ring. A special feature of the station is the use of a one-coordinate detector (OD-3M) in a powder diffractometer. The detector consists of a multiwire proportional gas chamber, a recording unit with a coordinate processor, and a computer. Single-axis detectors record scattered radiation simultaneously in a certain range of angles $\left(\sim 30^{\circ} \mathrm{C}\right)$ over 3328 channels, with a response rate up to $10 \mathrm{MHz}$. The test sample was placed in a chamber that was evacuated to a pressure below $10^{-4} \mathrm{~Pa}$. The sample was heated linearly in the range of 30 to $750{ }^{\circ} \mathrm{C}$, at a heating rate of $6^{\circ} \mathrm{C} / \mathrm{min}$. The recording of the diffractograms was carried out every minute of heating, meaning every $6{ }^{\circ} \mathrm{C}$. The wave length of synchrotron radiation was $1.0102 \AA$. The processing of the measured diffractograms and the identification of reflexes were carried out using PDF-2-search-match, FullProf, and Crystallographica. The technique development was assessed on hydrogen analyzer RHEN602 using LECO (LECO, Saint Joseph, MI, USA).

\section{Results and Discussion}

Stepwise heating was used to analyze the samples with high hydrogen concentration without exceeding the upper threshold of sensitivity of the thermocondimetric cell. First, the initial value of the current applied to the sample was determined from the melting degree of the flux. Tin was used as a fluxing agent in this analyzer. Flux was used to bring heat uniformly throughout the volume of the solid sample and to ensure the particulate sample would not be blown from the crucible during analysis. The melting of the flux began at the current strength of $170 \mathrm{~A}$. During the analysis, it was determined that the current strength should not exceed $700 \mathrm{~A}$, since the degassing process takes place at the given current strength. Therefore, $650 \mathrm{~A}$ was chosen as the current strength's extreme value. Next, the interval 170-650 A was divided into steps; a total of three routes with dimensions of 30, 60, and $120 \mathrm{~A}$ were selected. For each step, the holding time was $20 \mathrm{~s}$ and the time of the current increase was $15 \mathrm{~s}$. Thus, for different routes, the total analysis time was different $(600,250$, and $150 \mathrm{~s}$ at 30, 60, and $120 \mathrm{~A}$, respectively).

Furthermore, the time parameters were chosen. The analysis time was determined to be the total heating and holding times at constant current strength. To determine the optimum heating and holding time, another experiment was performed. The main fitting of time parameters was the analysis duration, particularly for the maximum mass of the test sample. We assumed that the heating time should not exceed or be equal to the holding time. The minimum heating time was $10 \mathrm{~s}$, although this was not enough time for heating in each stage. Therefore, the heating time of $10 \mathrm{~s}$ was selected, since during the given time, the hydrogen was uniformly detected by the sensor. The fitting 
of the holding time began at $15 \mathrm{~s}$, but the higher the current strength, the more the sample heated up, and when the exposure took place at the given current, the sensitivity threshold was exceeded. As has already been noted, we did not want the analysis process to take much time, so the optimal holding time was $20 \mathrm{~s}$ and the heating time was $15 \mathrm{~s}$. It should also be mentioned that with the selected time parameters, the mass of the test sample was $0.035 \mathrm{~g}$, which is greater than other investigated parameters. The next step was to choose the step of the furnace heating. After analyzing the curve obtained by thermal desorption spectroscopy of zirconium alloy (Figure 1a), we established that the optimal step was $100{ }^{\circ} \mathrm{C}$ corresponding to $60 \mathrm{~A}$.

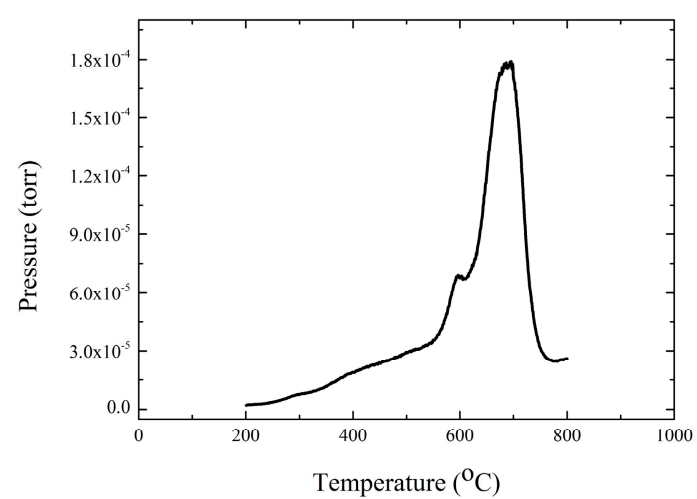

(a)

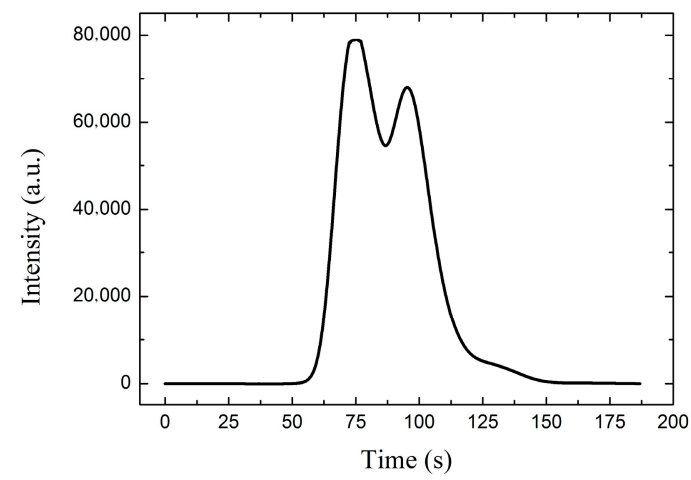

(b)

Figure 1. (a) Temperature programmed desorption curves of the titanium alloy and (b) the hydrogen extraction curve for the furnace heating current step $120 \mathrm{~A}$.

Analysis of previous works [53-58] demonstrated that the first peak of titanium alloy hydrogen desorption is observed at $600^{\circ} \mathrm{C}$. This temperature corresponds to the phase boundary between phases $\delta$ and $\beta+\delta$. Hence, during this TPD step, dissociation of hydrides occurs. Another high-temperature peak between 690 to $720{ }^{\circ} \mathrm{C}$ corresponds to the transition from the $\alpha$-phase to the $\beta$-phase.

A preliminary step was conducted to determine the temperature dependence of hydrogen for each peak. This was accomplished by melting the material in an inert gas atmosphere at a heating furnace stepwise, with a step of $120^{\circ} \mathrm{C}$ (Figure $1 \mathrm{~b}$ ). Thus, after the experiment, we determined that the first peak aligns with the dissociation hydride. The high temperature peak occurred at $1000{ }^{\circ} \mathrm{C}$.

Additionally, we performed an in-situ study of phase transitions of titanium hydride powder having stoichiometry of $\mathrm{TiH}_{2}(4 \mathrm{wt} \%)$. The results are shown in Figure 2.

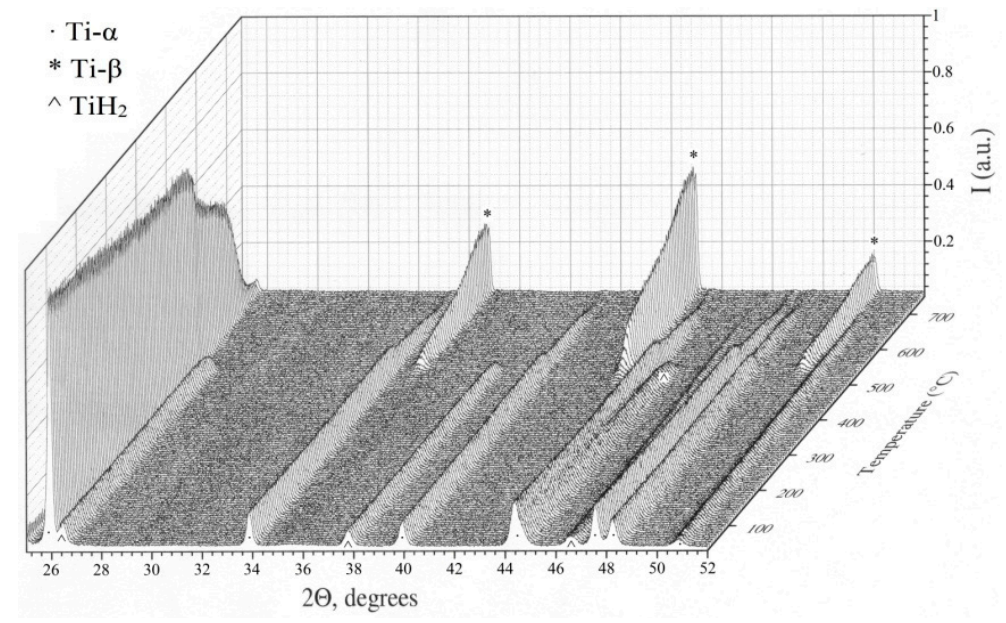

Figure 2. Kinetics of phase transitions during thermal exposure in titanium powder after hydrogen saturation from a gaseous medium. 
Figure 3 shows a diffraction pattern that reveals the kinetics of phase transitions of titanium alloy samples after their saturation with hydrogen from a gaseous medium during thermal exposure. With a linear heating of $6{ }^{\circ} \mathrm{C} / \mathrm{min}$, the decrease in intensity of titanium hydride reflections began at $520^{\circ} \mathrm{C}$. At $530^{\circ} \mathrm{C}$, these reflections disappeared almost completely, and hydrogen desorption began (Figure 1a). The dissociation temperature of hydrides at $530{ }^{\circ} \mathrm{C}$ corresponds to the boundary between the $\delta$ and $\beta+\delta$ phases. Throughout the volume of the material, the saturation of the titanium alloy with hydrogen from a gaseous medium was the formation of hydrides.

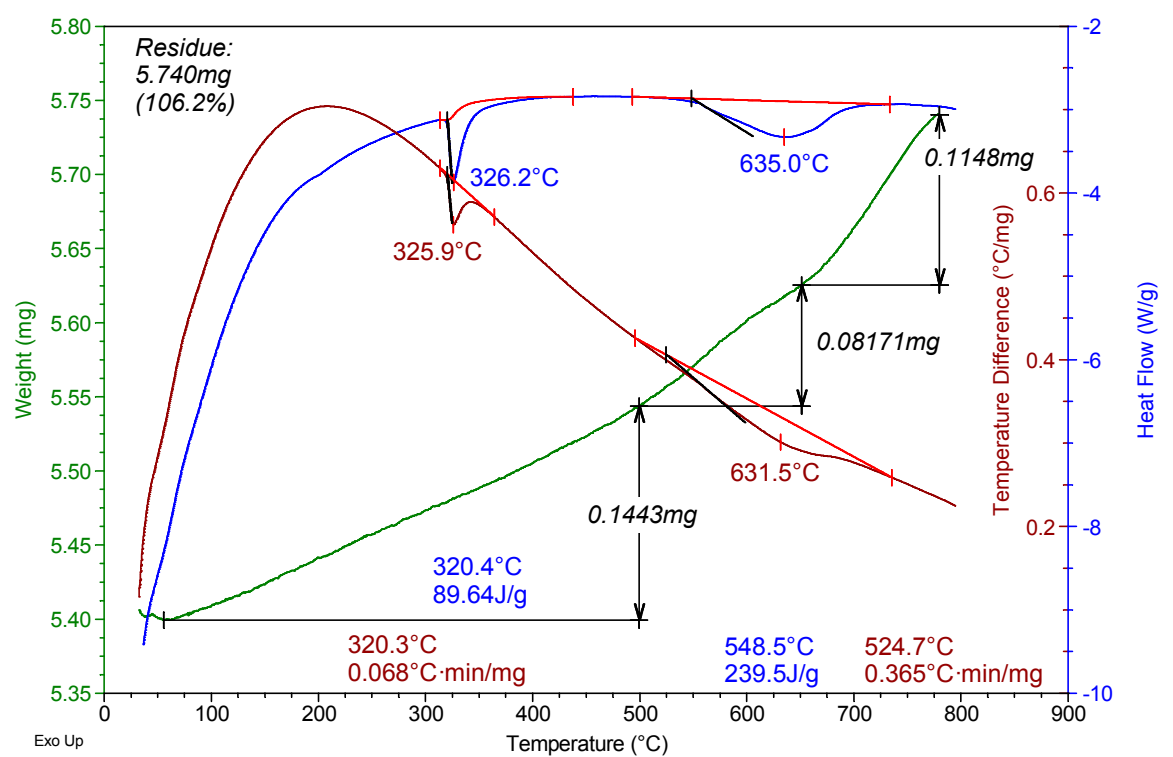

(a)

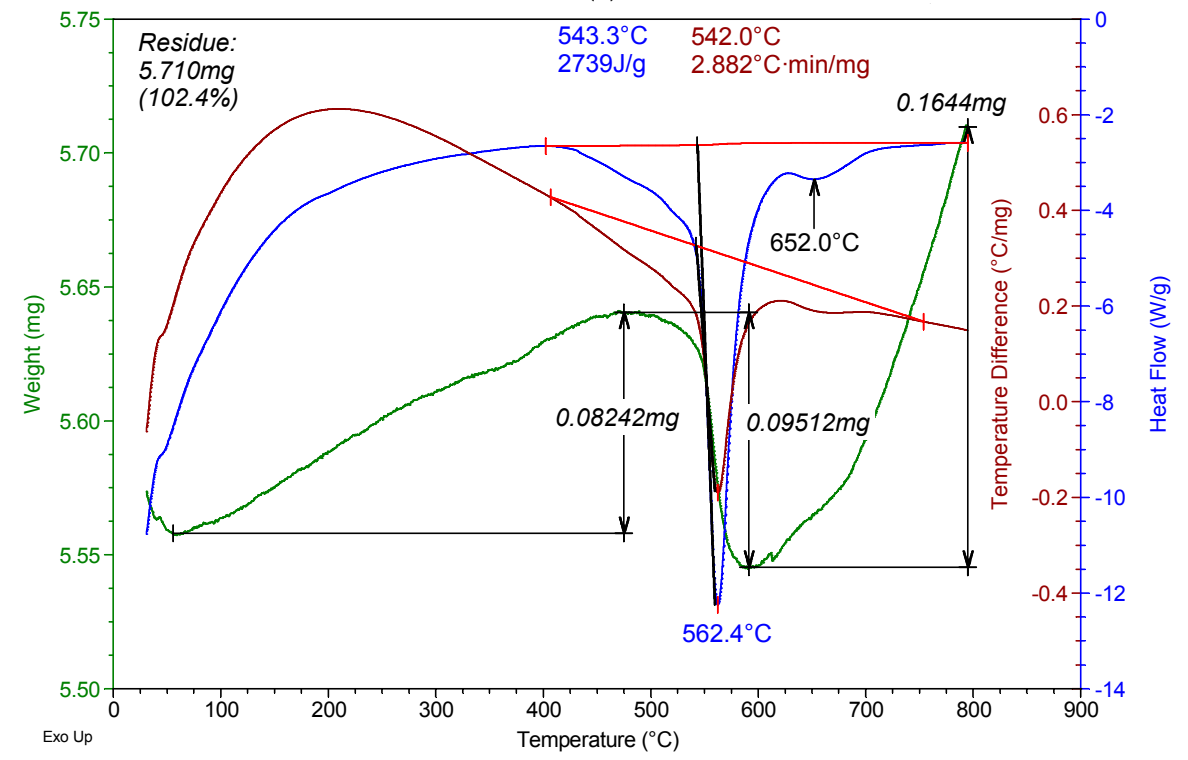

(b)

Figure 3. Thermogravimetric-curve of commercially pure titanium powder (a) before and (b) after hydrogenation.

Furthermore, an increase in temperature beyond $530{ }^{\circ} \mathrm{C}$ correlated with a decrease in reflection intensity of the titanium's $\alpha$-phase and an increase in reflection intensity of the titanium's $\beta$-phase. This correlation indicates the gradual transition of titanium from $\alpha$ - to $\beta$-modification. At $690-720{ }^{\circ} \mathrm{C}$, 
the $\alpha$-titanium phase passed completely into the $\beta$-titanium phase, leading to another peak appearing on thermostimulated hydrogen desorption spectrum (Figure 1a).

We performed a thermogravimetric analysis (TGA) of pure titanium powder without hydrogen, in addition to a saturation with hydrogen at the maximum concentration (4 wt \%) (Figure 3).

According to the results of thermal analysis, the original titanium powder, before hydrogenation and when heated in air, was characterized by a gradual increase in the sample's mass. When heated to $800{ }^{\circ} \mathrm{C}$, the total weight gain was $6.2 \%$. A light increase in mass was the result of the slowly oxidized titanium powder when heated in air (Figure 3a).

The heat flow from the sample had two pronounced endoeffects. At 320.4 and $524.7{ }^{\circ} \mathrm{C}$, the endoeffects did not cause a change in the oxidized titanium powder. Additionally, there were no pronounced deviations in the mass change curve accompanying the endoeffects. Thus, these endoeffects refer to phase transitions in the structure of the titanium particles themselves. The most probable endoeffects are the phase transitions (recrystallization) in the oxide shell covering the titanium powder.

After the titanium powder had been saturated with hydrogen, a significant endoeffect $(2739 \mathrm{~J} / \mathrm{g})$ was recorded using differential thermal analysis. The endoeffect was accompanied by a $1.66 \%$ decrease in the sample's mass (by $0.2 \%$ relative to the initial mass of the sample). This endoeffect, accompanied by a decrease in the sample's mass, arose when the hydrogenated powder was heated and the titanium hydride decomposed (Figure 3b).

Temperature dependence for each hydrogen peak was determined by melting hydrogen content in an inert gas atmosphere, heating the furnace stepwise at steps of $100{ }^{\circ} \mathrm{C}$. Thus, as the result of the performed experiment, we established that the first peak was related to the dissociation of hydrides. However, the high temperature peak was related to $1000{ }^{\circ} \mathrm{C}$. Additionally, we concluded that the heating step of $100^{\circ} \mathrm{C}$ was optimal for the development of the technique. For comparison, heating steps of 200 and $50^{\circ} \mathrm{C}$, which are equivalent to $120 \mathrm{~A}$ and $30 \mathrm{~A}$, were evaluated. Notably, the transfer of small currents into the temperature may result in a greater confidence interval, in the span of error.

Figure 4 presents hydrogen extraction curves with heating steps of $200{ }^{\circ} \mathrm{C}(120 \mathrm{~A}), 100{ }^{\circ} \mathrm{C}(60 \mathrm{~A})$, and $50{ }^{\circ} \mathrm{C}(30 \mathrm{~A})$.

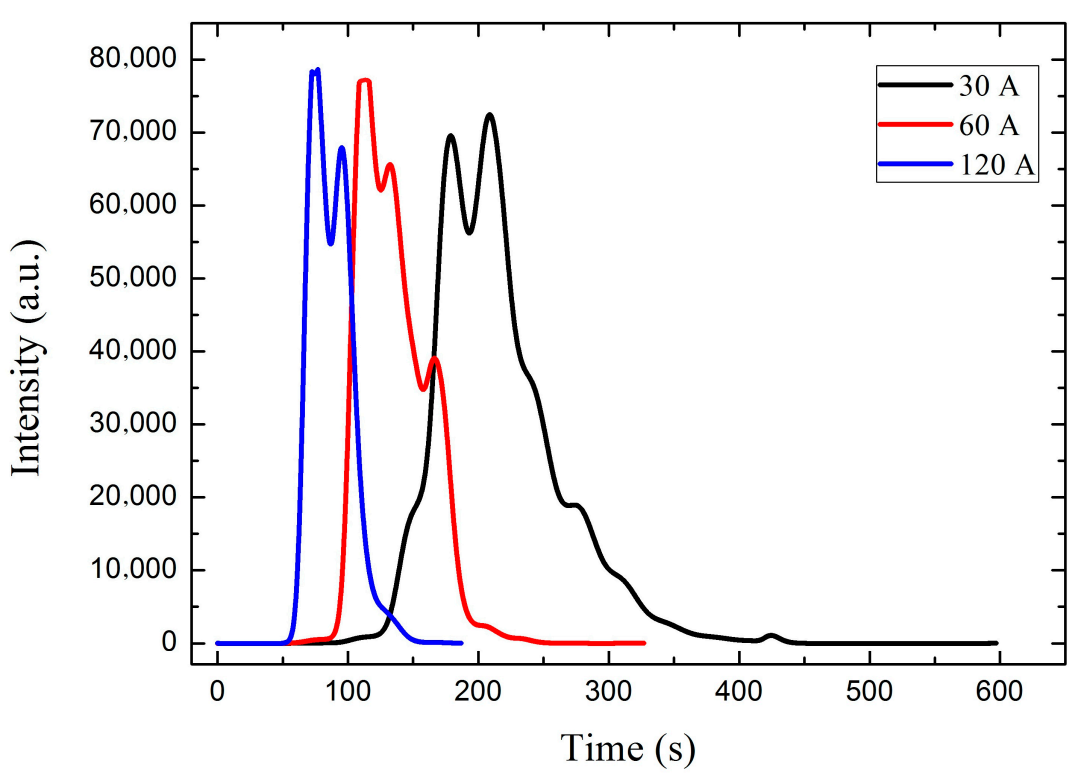

Figure 4. Hydrogen extraction curves with heating steps of $200^{\circ} \mathrm{C}(120 \mathrm{~A}), 100{ }^{\circ} \mathrm{C}(60 \mathrm{~A})$, and $50{ }^{\circ} \mathrm{C}$ (30 A).

After fitting the time parameters for each step, it was necessary to determine the maximum possible sample mass for each measured step (Table 2). 
Table 2. Sample mass for each measured step.

\begin{tabular}{ccccc}
\hline Step & Mass $\mathbf{0 . 0 1} \pm \mathbf{0 . 0 0 2} \mathbf{g}$ & Mass $\mathbf{0 . 0 2} \pm \mathbf{0 . 0 0 2} \mathbf{g}$ & Mass $\mathbf{0 . 0 3} \pm \mathbf{0 . 0 0 2} \mathbf{g}$ & Mass $\mathbf{0 . 0 4} \pm \mathbf{0 . 0 0 2} \mathbf{g}$ \\
\hline $1(120 \mathrm{~A})$ & + & + & - & - \\
$2(60 \mathrm{~A})$ & + & + & + & - \\
$3(30 \mathrm{~A})$ & + & + & + & + \\
\hline
\end{tabular}

According to the presented results, we obtained the following findings:

Step 1. At a furnace heating step of $200{ }^{\circ} \mathrm{C}(120 \mathrm{~A})$, the measured weight of the sample was $0.02 \mathrm{~g}$. It was not necessary to carry out the measurements in this mode.

Step 2. At a furnace heating step of $100{ }^{\circ} \mathrm{C}(60 \mathrm{~A})$, the maximum sample mass to measure hydrogen concentration was $0.03 \mathrm{~g}$; the analysis time was optimally fitted for measurements.

Step 3. At a furnace heating step of $50{ }^{\circ} \mathrm{C}(30 \mathrm{~A})$, the maximum sample mass was $0.04 \mathrm{~g}$. Given that the maximum analysis time could not exceed $600 \mathrm{~s}$, these settings could not be selected as the basic settings for measurement, since the process of determining the hydrogen content in the material cannot be prolonged over time.

In order to establish accuracy in the developed procedure, we needed to know a material's exact concentration, since the technique was developed to measure high concentration. In this case, the material also had to have a known high hydrogen concentration. For such concentrations, the gravimetric method can serve as an external method for determining hydrogen content. Furthermore, it was necessary to know the mass of the material before and after saturation. This represents a main limitation of this method, especially when comparing it to the method of melting the sample in an inert gas environment. In the latter case, it is not necessary to know the mass value before saturation.

The calibration line was obtained as a result of the calibration of obtained samples. The developed procedure reliability was evaluated using stoichiometric zirconium hydride $\left(\mathrm{ZrH}_{2}\right)$ (Figure 5).

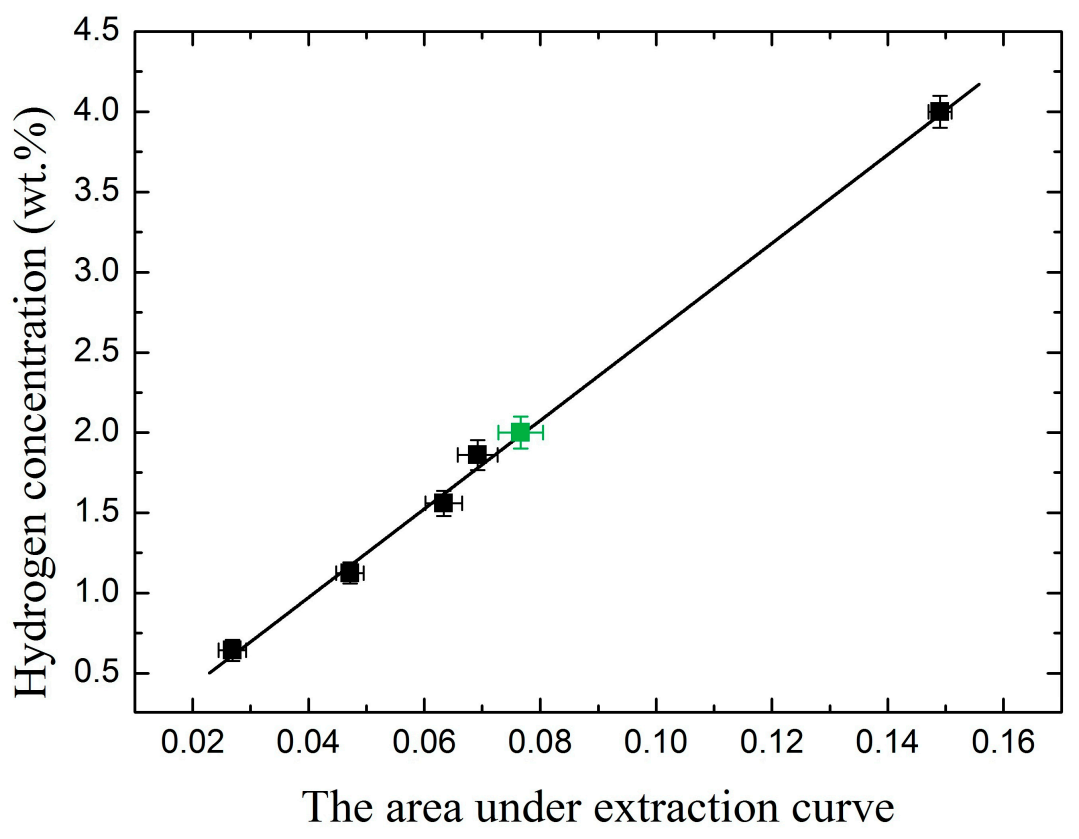

Figure 5. The developed procedure reliability evaluation.

The measured concentration in stoichiometric zirconium hydride lies on the calibration line. Thus, we concluded that the developed technique for measuring high concentrations of hydrogen is reliable and satisfies the stated goal. 


\section{Conclusions}

In this study, a technique was developed to measure high hydrogen concentrations with a hydrogen analyzer, RHEN602 using LECO. Over the course of the study, we performed the following procedures: (1) The series of the calibration samples were prepared within the concentration range of up to $4 \mathrm{wt} \%$ hydrogen; (2) Optimal parameters for measuring high concentrations of hydrogen were selected, such as establishing heating and holding times of 15 and $20 \mathrm{~s}$, setting the step of the furnace heating current at $60 \mathrm{~A}$, and having samples weigh in at is $0.030 \pm 0.001 \mathrm{~g}$; (3) The analyzer was calibrated according to the obtained calibration samples. We established that the developed technique can be used when measuring hydrogen content from 0.5 to $4 \mathrm{wt} \%$ hydrogen. (4) The reliability was evaluated using stoichiometric zirconium hydride. When measuring the samples, all obtained data was placed within a confidence interval of $10 \%$. Based on the presented results, we concluded that the developed technique meets the stated goal and can be applied for further research.

Author Contributions: M.N.B. analyzed the results, prepared the paper, directed the work, and carried out the calibration of RHEN602 using LECO. M.N.B. and V.N.K. performed sample preparation, hydrogen concentration determination, hydrogenation of samples, and revised the manuscript. A.M.L. and A.V.M. carried out testing of calibration samples and analyzed the results.

Funding: The study is supported by the Ministry of Education and Science of the Russian Federation, Project No. 11.1928.2017/4.6.

Acknowledgments: The research was carried out within the framework of the grant of the Program for Enhancing Competitiveness of Tomsk Polytechnic University.

Conflicts of Interest: The authors declare no conflict of interest.

\section{References}

1. Borzenko, V.; Eronin, A. The use of air as heating agent in hydrogen metal hydride storage coupled with PEM fuel cell. Int. J. Hydrogen Energy 2016, 41, 23120-23124. [CrossRef]

2. García-Triviño, P.; Fernández-Ramírez, L.M.; Gil-Mena, A.J.; Llorens-Iborra, F.; García-Vázquez, C.A.; Jurado, F. Optimized operation combining costs, efficiency and lifetime of a hybrid renewable energy system with energy storage by battery and hydrogen in grid-connected applications. Int. J. Hydrogen Energy 2016, 41, 23132-23144.

3. Ortiz, A.L.; Zaragoza, M.J.M.; Collins-Martínez, V. Hydrogen production research in Mexico: A review. Int. J. Hydrogen Energy 2016, 41, 23363-23379. [CrossRef]

4. Ramírez-Dámaso, G.; Ramírez-Platón, I.E.; López-Chávez, E.; Castillo-Alvarado, F.L.; Cruz-Torres, A.; Caballero, F.; Mondragón-Guzmán, R.; Rojas-Hernández, E. A DFT study of hydrogen storage on surface (110) of $\mathrm{Mg}_{1-x} \mathrm{Al}_{x}(0 \leq x \leq 0.1)$. Int. J. Hydrogen Energy 2016, 41, 23388-23393.

5. Ortiz, A.L.; Sámano, R.P.; Zaragoza, M.M.; Collins-Martínez, V. Thermodynamic analysis and process simulation for the $\mathrm{H}_{2}$ production by dry reforming of ethanol with $\mathrm{CaCO}_{3}$. Int. J. Hydrogen Energy 2015, 40, 17172-17179. [CrossRef]

6. Liu, W.; Aguey-Zinsou, K.F. Hydrogen storage properties of in-situ stabilised magnesium nanoparticles generated by electroless reduction with alkali metals. Int. J. Hydrogen Energy 2015, 40, 16948-16960. [CrossRef]

7. Bouazizi, N.; Boudharaa, T.; Bargougui, R.; Vieillard, J.; Ammar, S.; Le Derf, F.; Azzouz, A. Synthesis and properties of ZnO-HMD@ZnO-Fe/Cu core-shell as advanced material for hydrogen storage. J. Colloids Interface Sci. 2017, 491, 89-97. [CrossRef] [PubMed]

8. Köse, D.A.; Yurdakul, Ö.; Şahin, O.; Öztürk, Z. The new metal complex templated polyoxoborate(s) (POB(s)) structures. Synthesis, structural characterization, and hydrogen storage capacities. J. Mol. Struct. 2017, 1134, 809-813.

9. Kolachev, B.A.; Shalin, R.E.; Ilin, A.A. Hydrogen Storage Alloys; Metallurgy: Moscow, Russia, $1995 ;$ p. 384. (In Russian)

10. Zhang, Y.; Li, J.; Zhang, T.; Wu, T.; Kou, H.; Xue, X. Hydrogenation thermokinetics and activation behavior of non-stoichiometric Zr-based Laves alloys with enhanced hydrogen storage capacity. J. Alloys Compd. 2017, 694, 300-308. [CrossRef] 
11. Suárez-Alcántara, K.; Palacios-Lazcano, A.F.; Funatsu, T.; Cabañas-Moreno, J.G. Hydriding and dehydriding in air-exposed Mg Fe powder mixtures. Int. J. Hydrogen Energy 2016, 41, 23380-23387.

12. Chen, X.; Zou, J.; Zeng, X.; Ding, W. Hydrogen storage properties of a Mg-La-Fe-H nano-composite prepared through reactive ball milling. J. Alloys Compd. 2017, 701, 208-214. [CrossRef]

13. Ma, M.; Duan, R.; Ouyang, L.; Zhu, X.; Chen, Z.; Peng, C.; Zhu, M. Hydrogen storage and hydrogen generation properties of $\mathrm{CaMg}_{2}$-based alloys. J. Alloys Compd. 2017, 691, 929-935. [CrossRef]

14. Suárez-Alcántara, K.; Palacios-Lazcano, A.F.; Funatsu, T.; Cabañas-Moreno, J.G. Mg-M-LiH alloys prepared by mechanical milling and their hydrogen storage characteristics. Int. J. Hydrogen Energy 2015, 40, 17344-17353.

15. Hino, S.; Grove, H.; Ichikawa, T.; Kojima, Y.; Sørby, M.H.; Hauback, B.C. Metal aluminum amides for hydrogen storage-Crystal structure studies. Int. J. Hydrogen Energy 2015, 40, 16938-16947. [CrossRef]

16. Tarasov, B.P.; Lototsky, M.V.; Yartys, V.A. The problem of hydrogen storage and the prospects for using hydrides for the accumulation of hydrogen. Russ. Chem. J. 2006, 50, 34-48. (In Russian)

17. Kulik, O.P.; Chernyshev, L.I. Hydrogen Energy: Storage and Transportation of Hydrogen (Review); Frantsevich, I.N., Ed.; Preprint of NAS of Ukraine; Institute of Problems of Materials Science: Ukraine, Ukraine; pp. 1-67. (In Russian)

18. Pundt, A.; Kirchheim, R. Hydrogen in metals: Microstructural aspects. Annu. Rev. Mater. Res. 2006, 36, 555-608. [CrossRef]

19. Wang, L.; Jiang, J.; Ma, A.; Li, Y.; Song, D.A. Critical Review of Mg-Based Hydrogen Storage Materials Processed by Equal Channel Angular Pressing. Metals 2017, 7, 324. [CrossRef]

20. Da Silva Dupim, I.; Ferreira Santos, S.; Huot, J. Effect of Cold Rolling on the Hydrogen Desorption Behavior of Binary Metal Hydride Powders under Microwave Irradiation. Metals 2015, 5, 2021-2033. [CrossRef]

21. Perevezentsev, A.N.; Andreev, B.M.; Kapyshev, V.K.; Rivkis, L.A.; Malek, M.P.; Bystritskii, V.M.; Stolupin, V.A. Hydrides of intermetallic compounds and alloys, their properties and applications in nuclear engineering. Phys. Elem. Part. Atom. Nucl. 1988, 19, 1386. (In Russian)

22. Azhazh, V.M.; Tikhonovsky, M.A.; Shepelev, A.G.; Kurilo, Yu.P.; Ponomarenko, T.A.; Vinogradov, D.V. Materials for hydrogen storage: Analysis of the development trend on the basis of data on information flows. Q. Atom. Sci. Technol. 2006, 1, 145-152. (In Russian)

23. Milanović, I.; Milošević, S.; Rašković-Lovre, Ž.; Novaković, N.; Vujasin, R.; Matović, L.; Fernándezc, J.F.; Sánchez, C.; Novaković, J.G. Microstructure and hydrogen storage properties of $\mathrm{MgH}_{2}-\mathrm{TiB}_{2}-\mathrm{SiC}$ composites. Ceram. Int. 2013, 39, 4399-4405.

24. Fernandez, A.; Deprez, E.; Friedrichs, O. A comparative study of the role of additive in the $\mathrm{MgH}_{2}$ vs. the $\mathrm{LiBH}_{4}-\mathrm{MgH}_{2}$ hydrogen storage system. Int. J. Hydrogen Energy 2011, 36, 3932-3940. [CrossRef]

25. Friedrichs, O.; Kolodziejczyk, L.; Sánchez-López, J.C.; Fernandez, A.; Lyubenova, L.; Zander, D.; Köster, U.; Aguey-Zinsoud, K.F.; Klassen, T.; Bormann, R. Influence of particle size on electrochemical and gas-phase hydrogen storage in nanocrystalline Mg. J. Alloys Compd. 2008, 463, 539-545. [CrossRef]

26. Leardini, F.; Bodega, J.; Ares, J.R.; Fernandez, J.F. Realistic simulation in a single stage hydrogen compressor based on $\mathrm{AB}_{2}$ alloys. Int. J. Hydrogen Energy 2016, 41, 9780-9788.

27. Kumar, S.; Jain, A.; Ichikawa, T.; Kojima, Y.; Dey, G.K. Development of vanadium based hydrogen storage material: A review. Renew. Sustain. Energy Rev. 2017, 72, 791-800. [CrossRef]

28. Shao, H.; Xin, G.; Zheng, J.; Li, X.; Akiba, E. Nanotechnology in Mg-based materials for hydrogen storage. Nano Energy 2012, 1, 590-601. [CrossRef]

29. Zhang, T.; Zhang, Y.; Zhang, M.; Hu, R.; Kou, H.; Li, J.; Xue, X. Hydrogen absorption behavior of Zr-based getter materials with Pd Ag coating against gaseous impurities. Int. J. Hydrogen Energy 2016, 41, 14778-14787. [CrossRef]

30. Tarnawski, Z.; Kim-Ngan, N.T.H. Hydrogen storage characteristics of Ti-and V-based thin films. J. Sci. Adv. Mater. Dev. 2016, 1, 141-146. [CrossRef]

31. Protsenko, O.M. Experience in developing a methodology for measuring hydrogen content in titanium alloys. Electron. Sci. J. 2014, 12, 1-5. (In Russian)

32. Grigorovich, K.V. New possibilities of modern methods for determination of gas-forming impurities in metals. Diag. Mater. 2007, 73, 23-34. (In Russian)

33. Furuya, Y.; Takasaki, A.; Mizuno, K.; Yoshiie, T. Hydrogen desorption from pure titanium with different concentration levels of hydrogen. J. Alloys Compd. 2007, 446, 447-450. [CrossRef] 
34. Eliezer, D.; Tal-Gutelmacher, E.; Cross, C.E.; Boellinghaus, T. Hydrogen absorption and desorption in a duplex-annealed Ti-6Al-4V alloy during exposure to different hydrogen-containing environments. Mater. Sci. Eng. A 2006, 433, 298-304. [CrossRef]

35. Tal-Gutelmacher, E.; Eliezer, D.; Abramov, E. Thermal desorption spectroscopy (TDS)—Application in quantitative study of hydrogen evolution and trapping in crystalline and non-crystalline materials. Mater. Sci. Eng. A 2007, 445, 625-631. [CrossRef]

36. Von Zeppelin, F.; Haluška, M.; Hirscher, M. Thermal desorption spectroscopy as a quantitative tool to determine the hydrogen content in solids. Thermochim. Acta 2003, 404, 251-258. [CrossRef]

37. Takasaki, A.; Furuya, Y.; Ojima, K.; Taneda, Y. Hydride dissociation and hydrogen evolution behavior of electrochemically charged pure titanium. J. Alloys Compd. 1995, 224, 269-273. [CrossRef]

38. Determination of Total and Surface Hydrogen by Melting in an Inert Gas Atmosphere: [Electronic Resource]. LECO Corporation-Representative Office in Russia, 2012. Available online: http:/ / ru.leco-europe.com/ product/rhen602/ (accessed on 27 August 2018). (In Russian)

39. Mikhaylov, A.A.; Laptev, R.S.; Kudiiarov, V.N.; Volokitina, T.L. Titanium defect structure change after gas-phase hydrogenation at different temperatures and cooling rates. AIP Conf. Proc. 2016, 1783, 020152.

40. Hadjixenophontos, E.; Michalek, L.; Roussel, M.; Hirscher, M.; Schmitz, G. The role of surface oxides on hydrogen sorption kinetics in titanium thin films. Appl. Surf. Sci. 2018, 441, 324-330. [CrossRef]

41. Laptev, R.; Lider, A.; Bordulev, Y.; Kudiiarov, V.; Garanin, G. Hydrogenation-induced microstructure changes in titanium. J. Alloys Compd. 2015, 645, S193-S195. [CrossRef]

42. Stepanova, E.; Bordulev, Y.; Kudiiarov, V.; Laptev, R.; Lider, A.; Jiang, X. Effect of hydrogen on the structural and phase state and defect structure of titanium Alloys. AIP Conf. Proc. 2016, 1772, 030016.

43. Sakintuna, B.; Lamari-Darkrim, F.; Hirscher, M. Metal hydride materials for solid hydrogen storage: A review. Int. J. Hydrogen Energy 2007, 32, 1121-1140. [CrossRef]

44. Larionov, V.V.; Lider, A.M.; Laptev, R.S. Control of changes in the defect structure of titanium saturated with hydrogen. IOP Conf. Ser. Mater. Sci. Eng. 2016, 135, 012025. [CrossRef]

45. Ulmer, U.; Dieterich, M.; Pohl, A.; Dittmeyer, R.; Linder, M.; Fichtner, M. Study of the structural, thermodynamic and cyclic effects of vanadium and titanium substitution in laves-phase $\mathrm{AB}_{2}$ hydrogen storage alloys. Int. J. Hydrogen Energy 2017, 42, 20103-20110. [CrossRef]

46. Macin, V.; Christ, H.J. Influence of hydride-induced microstructure modification on mechanical properties of metastable beta titanium alloy Ti 10V-2Fe-3Al. Int. J. Hydrogen Energy 2015, 40, 16878-16891. [CrossRef]

47. Vizcaíno, P.; Vergara, I.L.; Banchik, A.D.; Abriata, J.P. Terminal solid solubility determinations in the H-Ti system. Int. J. Hydrogen Energy 2015, 40, 16928-16937.

48. San-Martin, A.; Manchester, F.D. The H-Ti (Hydrogen-Titanium) system. Bull. Alloy Phase Diagr. 1987, 8, 30-42. [CrossRef]

49. Kudiiarov, V.N.; Babihina, M.N.; Gvozdyakov, D.V. The Influence of Gas-Phase Hydrogenation Parameters on the Processes of Activation, Sorption and Accumulation of Hydrogen in the Powder of Pure Titanium. MATEC Web Conf. 2016, 72, 01054. [CrossRef]

50. Kolthoff, I.M.; Stenger, V.A. Volumetric Analysis; Interscience Publishers, Inc.: Olney, UK, 1947.

51. Methodical Instructions to Laboratory Work on Analytical Chemistry "Gravimetric Methods of Analysis"; Comp. T.N. Ermolaeva.-Lipetsk; LSTU: Lipetsk, Russia, 2004; p. 35. (In Russian)

52. Manakhova, S.V. Fundamentals of quantitative analysis: Textbook. In Allowance; Northern (Arctic) Federal University: Arkhangelsk, Russia, 2010; p. 128. (In Russian)

53. Denisov, E.A.; Kompaniets, M.V.; Kompaniets, T.N.; Spitsyn, V.I. Surface-limited permeation regime in the study of hydrogen interactions with metals. Measurement 2018, 117, 258-265. [CrossRef]

54. Nikitenkov, N.N.; Chernov, I.P.; Tyurin, Y.I.; Skirnevsky, A.V.; Garanin, G.V.; Lider, A.M.; Cherdantsev, Y.P. Studies of hydrogen storage in a zirconium alloy by the method of thermally stimulated gas evolution. Proc. Tomsk Polytech. Univ. 2006, 309, 52-55. (In Russian)

55. Woodruff, D.; Delchar, T. Modern Methods of Surface Investigation; Cambridge University Press: Cambridge, UK, 1989; p. 564.

56. Hultquist, G.; Graham, M.J.; Smialek, J.L.; Jönsson, B. Hydrogen in metals studied by thermal desorption spectroscopy (TDS). Corros. Sci. 2015, 93, 324-326. [CrossRef] 
57. Ma, M.; Liang, L.; Tang, B.; Xiang, W.; Wang, Y.; Cheng, Y.; Tan, X. Decomposition kinetics study of zirconium hydride by interrupted thermal desorption spectroscopy. J. Alloys Compd. 2015, 645, S217-S220. [CrossRef]

58. Ershova, O.G.; Dobrovolsky, V.D.; Solonin, Y.M.; Khyzhun, O.Y. Hydrogen-sorption and thermodynamic characteristics of mechanically grinded $\mathrm{TiH} 1.9$ as studied using thermal desorption spectroscopy. J. Alloys Compd. 2011, 509, 128-133. [CrossRef] 